\title{
FULLY INTEGRATED Ka/K BAND HERMETIC RECEIVER MODULE
}

\author{
M.C.Comparini, M.Feudale, J.R.Linkowski, P.Ranieri, A.Suriani \\ Alenia Spazio S. p. A., RF and Microwave Engineering \\ Via Saccomuro 24, 00131 Rome, Italy \\ phone: 39-6-4151-2583 fax: 39-6-4151-2507 e-mail: j.linkowski@roma.alespazio.it
}

\begin{abstract}
This paper presents an Engineering Model of a fully integrated, hermetic receiver as developed for commercial space flight applications. Repeatable performance especially at $K$ band frequencies is difficult and costly in a production environment. State-of-the-art packaging technology and a family of dedicated MMICs were employed in order to guarantee performance as well as reduce production and alignment costs. This combined with Alenia Spazios extensive, flight proven heritage, has produced a receiver aimed at both the transparent and regenerative payload markets.
\end{abstract}

\section{INTRODUCTION}

Alenia Spazio's long standing prominence in equipment design and production for payload applications has placed the company in a leading position to respond to needs of the next generation multimedia satellite programs. Specific expertise in $\mathrm{Ka}$ band subsystems and equipment matured since the development of the Olympus, Italsat F1 and Italsat F2 payloads, and the recently awarded ESA contract in the frame of the program "Components for Ka-band Telecommunications Equipment", has culminated with the $\mathrm{Ka} / \mathrm{K}$ band Receiver product. Direct heritage in $\mathrm{Ka}$ band equipment design and production is drawn moreover from several scientific programs where Alenia Spazio managed the $\mathrm{Ka}$ band $\mathrm{RF}$ Instrumentation Subsystems including a $34 \mathrm{GHz} 60$ $\mathrm{dB}$ LNA and downconverter designed and developed in house.

A complete Research and Development program is underway with the scope to design, develop and space qualify a complete line of Ka payload equipment using the latest technologies in microwave design and advanced packaging [1]. This includes next generation LNAs, channel amplifiers, down-converters as well as complete communication receivers for which this paper will describe in detail. The key element to the success of this unit is the development of a complete line of application specific MMICs [2]. This minimizes or totally eliminates post-production tuning which dramatically reduces production lead-time. Macro-hybrid packaging using "chip-and-wire" also eliminates the additional cost of individual packaged parts. This results in considerable overall cost savings when applied to moderate to high volume production runs. This R\&D effort is currently being supported by the European Space Agency with a contract specifically devoted to the development of MMICbased $\mathrm{Ka}$ band receivers, down converters, channel amplifiers and linearizers [3]. This paper concentrates on the $\mathrm{Ka}$ band receiver designed for transparent repeaters but, as will be described, the particular construction permits modifications necessary for multimedia, regenerative payloads $(\mathrm{Ka} / \mathrm{Ku})$. Eventual "derivatives" of the this receiver, considered during the design phase, will benefit from a large communality in design, technology applied, and functional blocks and, therefore, relatively easily implemented by changing various components and sub-circuits.

\section{EQUIPMENT DESCRIPTION}

The receiver amplifies with very low noise and down converts signals in the 27.5 to $30 \mathrm{GHz}$ range to the 17 to $19.5 \mathrm{GHz}$ range by mixing with an internally generated Local Oscillator. Auxiliary circuits include regulation and filtering of 3 secondary voltages. The receiver may be combined with Reference Oscillator, and $\mathrm{DC} / \mathrm{DC}$ converter to form a stand alone unit incorporating satellite main bus, telecommand and telemetry interface (Figure 1).

All receiver functions, including Microwave PhaseLock-Loop Oscillator (MPLLO) are contained in a hermetic, Kovar package (Figures $2 \& 3$ ). The package material provides a good thermal-mechanical match to allumina permitting hermetic "window" WG/ustrip transition and direct attachment of substrates, PHEMTs, and MMIC die which minimizes parasitic effects in the critical Ka-band chain. Hermetic bead coax transitions are utilized for RF transitions and DC feedthroughs. Distribution of secondary voltages and control signals is on non-hermetic side of module. A "discrete" 2-stage LNA followed by a MMIC LNA (Figure 8) provides adequate gain for stabilization and optimization of NF. The RF stage provides $35 \mathrm{~dB}$ of gain with as associated Noise Figure of $2.3 \mathrm{~dB}$ (Figure 5 - including input $\mathrm{W} / \mathrm{G}$ isolator). "Active" gate bias 
to discrete PHMET maintains drain current. An image reject filter follows to minimize noise contribution of relatively large band RF stages. The heart of the down conversion is a $30 / 20$ MMIC mixer optimized for rejection of the $2^{\text {nd }} \mathrm{LO}$ harmonic and related products (Figures 9, 10). The 17 to $19.5 \mathrm{GHz}$ IF chain is composed of a MMIC variable attenuator (Figure 11) for thermal compensation, same low noise and medium power MMIC amplifiers. Receiver conversion gain is maintained over temperature by a simple analog compensation network governed by a thermistor. Measured gain stability is $2.3 \mathrm{dBpp}$ over 20 to $70^{\circ} \mathrm{C} ; 1.1 \mathrm{dBpp}$ over -10 to $60^{\circ}$.

All devices of this subcircuit are brazed to a CopperTungsten carrier which may be substituted with a functionally similar, MMIC based $\mathrm{Ku}$ band stage for application on regenerative payloads. A MMIC version of the corresponding mixer has been developed and tested for integration in a 30/12 GHz Receiver.

The Frequency Generation section, or MPLLO, is an integration of open-carrier assemblies fabricated on thinfilm substrates, mounting IC and MMIC die, utilizing chip-and-wire technology. The LO generation concept is derived from Alenia Spazio's Ku-band TC\&R and Payload products and has been validated on a number of flight programs. The microwave phase-locked-loop (MPLLO) features a microwave frequency divider and a voltage controlled dielectric resonator oscillator (VCDRO), phase locked to an externally supplied VHF reference. The active element is a MMIC providing oscillator negative impedance + buffer stage at fundamental LO frequencies in the range of 9 to $11.5 \mathrm{GHz}$ (Figure 12). Free running phasenoise of the MMIC oscillator is better than 100 $\mathrm{dBc}$ at a $100 \mathrm{kHz}$ offset. Typical output power of the buffer is $>+10 \mathrm{dBm}$. The final LO drive level can be adjusted approximately between +4 and $+9 \mathrm{dBm}$ by inserting or bypassing especially designed $1 / 4$ wave resistive attenuators $(2 \times 2.5 \mathrm{~dB})$ photo-etched on interface MIC. The lower drive level was chosen in order to minimize $2 \times$ LO harmonic spur that results very close to the band.

The "MCM PLL" open carrier contains "active" analog phase detector, loop filter, gain compensation and associated voltage regulation. $\mathrm{Ku}$ band IF frequencies may be generated by adding a wideband MMIC doubler (recently developed and under test) to the output of the same MPLLO. The Temperature Compensated Reference Oscillator (TCXO) module employs a recurrent design from a qualified supplier, flight proven on numerous Programs. The DC/DC Converter Module is also a recurrent ALS design common to numerous programs.

The main performance attained by the $\mathrm{Ka} / \mathrm{K}$ Band Hybrid Receiver is summmarized against the requirements in (Table 1).

\section{PACKAGING DESIGN}

The Receiver module is conceived as a macrohybrid integrating all microwave and control functions in a single hermetic housing. The housing material is kovar. The electrical RF interfaces employ hermetic microstrip to waveguide launchers (for the RF port) or coaxial beads/feedthrus (IF output, LO test point port, crystal reference input, DC connections).

The microstrip to waveguide launcher is a ceramic substrate hermetically closing a waveguide aperture. Hermeticity is achieved by brazing a metallization ring on the bottom edges of the substrate to the aperture rim. Laser welding of the cover guarantees hermeticity.

MMIC circuits are brazed on copper-tungsten carriers. The carriers are either epoxy attached (LNA and IF strips, VCO) or screwed (mixer) onto the kovar housing. The mixer carrier is replaced during unit alignment by microstrip through-paths to a test connector, in order to separately align RF, IF and LO sections. The test connector's field replaceable flange is removed and replaced by a cover after alignment.

Passive ceramic substrates are epoxy attached directly to the kovar housing. MIC isolators have a kovar carrier that is epoxy attached to the housing.

\section{CONCLUSION}

An Engineering Model of a fully integrated, hermetic receiver has been developed and tested, demonstrating the advantage, in an eventual production environment, of state-of-the-art packaging technology and extensive application of MMIC functions. The main scope of the development was to guarentee repeatable performance, in particaular at Ka-band, and significantly reduce production and post-production alignment costs. Most main performance goals were met, especially the critical Noise Figure. The experience has also furnished valuable insight for further improvements. Module housing construction must be optimized and some complicated assembly steps simplified. Finally, repeatable RF performance will continue to rely more and more on dedicated MMIC building blocks.

\section{REFERENCES}

[1] M.C. Comparini, A. Suriani: "Microwave equipment technolgies for wideband $\mathrm{Ka}$ band satellite commication systems" - Fifth Ka Band Utilization Conference, Taormina, Italy, October 1999.

[2] M:C: Comparini et al.. "MMIC based Modules for Commercial Satellite Application"' European GaAs and related III-V compounds Application Symposium, Bologna, Italy, September 1997. 
[3] G. Gatti - ESA/ESTEC: "Application of GaAs MMICs in space: an ESA perspective", European GaAs and related III-V compounds Application Symposium, Bologna, Italy, September 1997.

\begin{tabular}{|c|c|c|c|}
\hline Parameter & Units & \begin{tabular}{|l|} 
Microwave \\
module \\
Objectives
\end{tabular} & Measured \\
\hline INPUT FREQ & $\mathrm{GHz}$ & within 27.5 -31.5 & $27.5-31.0$ \\
\hline LO FREQ & $\mathrm{GHz}$ & within 9-12 & \\
\hline $\begin{array}{l}\text { OUTPUT } \\
\text { FREQ }\end{array}$ & $\mathrm{GHz}$ & within $17.5-21.5$ & \\
\hline BANDWIDTH & $\mathrm{MHz}$ & 1000 & \\
\hline $\begin{array}{l}\text { NOISE } \\
\text { FIGURE }\end{array}$ & $d B$ & 2.5 & $\begin{array}{l}2.6 \text { at } 60^{\circ} \mathrm{C} \\
2.8 \text { at } 60^{\circ} \mathrm{C} \\
\text { (Figure } 6 \text { ) }\end{array}$ \\
\hline $\begin{array}{l}\text { INPUT } \\
\text { POWER }\end{array}$ & $\mathrm{dBm}$ & -55 & \\
\hline GAIN & $\mathrm{dB}$ & within $50-60$ & 55 (Figure 6) \\
\hline $\begin{array}{l}\text { GAIN } \\
\text { STABILITY }\end{array}$ & dBpp & 1 & \begin{tabular}{|l|}
$<2.3$ over - \\
$20 / 70^{\circ} \mathrm{C}$ \\
$<1.1$ over - \\
$10 / 60^{\circ} \mathrm{C}$ \\
\end{tabular} \\
\hline & & $0.2 / 10^{\circ} \mathrm{C}$ & \begin{tabular}{|l|} 
compliant over 0 \\
to $50^{\circ} \mathrm{C}$; up to 0.8 \\
over -20 to $70^{\circ} \mathrm{C}$
\end{tabular} \\
\hline $\begin{array}{l}\text { GAIN } \\
\text { FLATNESS }\end{array}$ & $\mathrm{dBpp}$ & $2 / 1000 \mathrm{MHz}$ & $\begin{array}{l}1.1 \text { amb } \\
1.8 \text { over temp }\end{array}$ \\
\hline & & $0.3 / 100 \mathrm{MHz}$ & compliant \\
\hline GAIN SLOPE & $\mathrm{dB} / \mathrm{MHz}$ & 0.01 & compliant \\
\hline $\begin{array}{l}\text { RF/IF } \\
\text { ISOLATION }\end{array}$ & $\mathrm{dBc}$ & 55 & $>55$ \\
\hline 3rd ORD. I.P. & $\mathrm{dBm}$ & 23.5 each carrier & 24 each carrier \\
\hline FREQ STAB & ppm & NA & \\
\hline $\begin{array}{l}\text { LO } \\
\text { HARMONICS }\end{array}$ & $\mathrm{dBm}$ & -15 & -1.5 \\
\hline \multirow[t]{2}{*}{$\begin{array}{l}\text { 1-TONE } \\
\text { INTERM. }\end{array}$} & $-d B c$ & 60 & $<-60$ \\
\hline & & 30 for $5 \mathrm{LO}-\mathrm{RF}$ & -21 \\
\hline \begin{tabular}{l|} 
PHASE \\
NOISE \\
\end{tabular} & $\mathrm{dBc}$ & & \\
\hline$@ 100 \mathrm{kHz}$ & & -100 & -102 unlocked \\
\hline$@ 1 \mathrm{MHz}$ & & -100 & $<-125$ \\
\hline $\begin{array}{l}\text { OVERDRIVE } \\
\text { I/P }\end{array}$ & $\mathrm{dBm}$ & -40 & OK \\
\hline MAX SAT. O/P & $\mathrm{dBm}$ & 25 & $<20$ (Figure 7) \\
\hline RET. LOSS & $d B$ & 21 & $<21$ \\
\hline AM/PM CONV. & $\operatorname{deg} / \mathrm{dB}$ & $0.2 @+5 \mathrm{dBm}$ & compliant \\
\hline $\begin{array}{l}\text { AM/PM } \\
\text { TRANSF. }\end{array}$ & $\operatorname{deg} / \mathrm{dB}$ & $0.2 @+5 \quad \&-15$ & compliant \\
\hline PHASE SHIFT & deg & 1 up to $+5 \mathrm{dBm}$ & not measured \\
\hline $\begin{array}{l}\text { POWER } \\
\text { CONSUMPT. }\end{array}$ & W & 5.3 (typ 4.8) & $<5.0$ \\
\hline MASS & $g$ & 220 & 220 \\
\hline $\begin{array}{l}\text { TEMP. } \\
\text { RANGE }\end{array}$ & ${ }^{\circ} \mathrm{C}$ & -20 to 65 & -20 to $70^{\circ} \mathrm{C}$ \\
\hline
\end{tabular}

Table 1: Receiver hybrid module performance summary

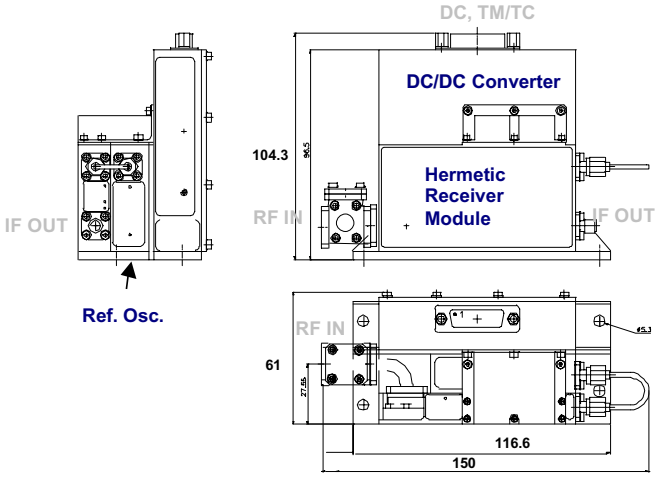

Fig. 1: Proposed stand alone Ka/K Receiver Unit

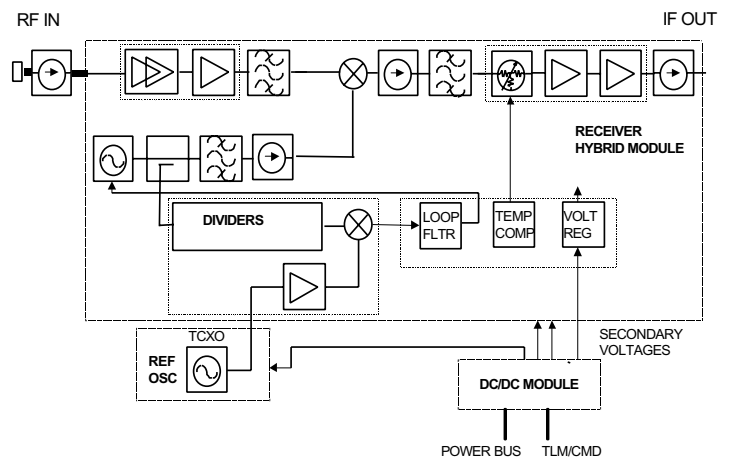

Fig. 2: Ka/K Receiver Functional Block Diagram

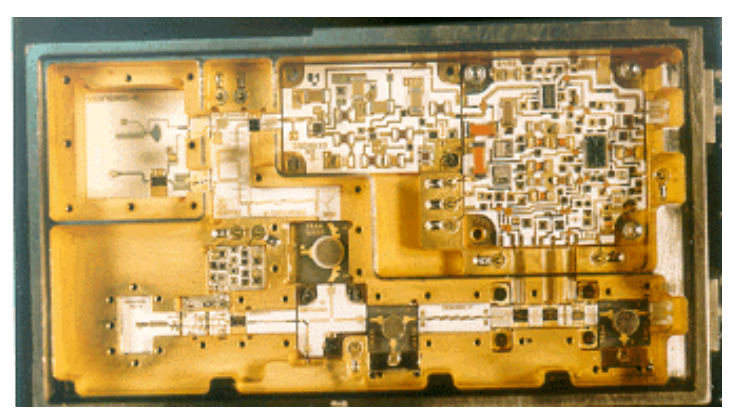

Fig. 3: Ka/K Receiver Assembly (90x50x15mm)

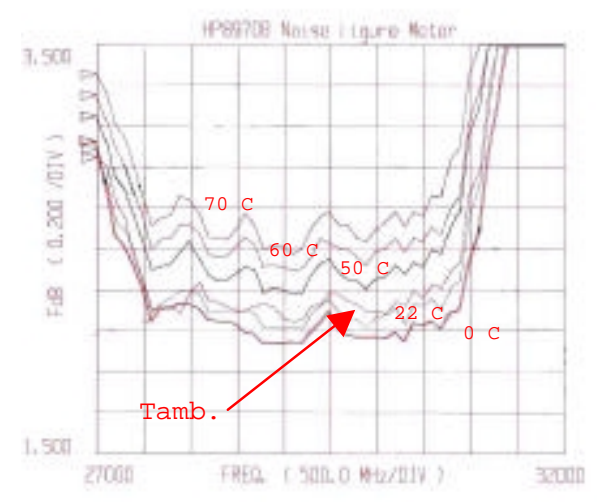

Fig. 4: Noise Figure of RF section in temperature 


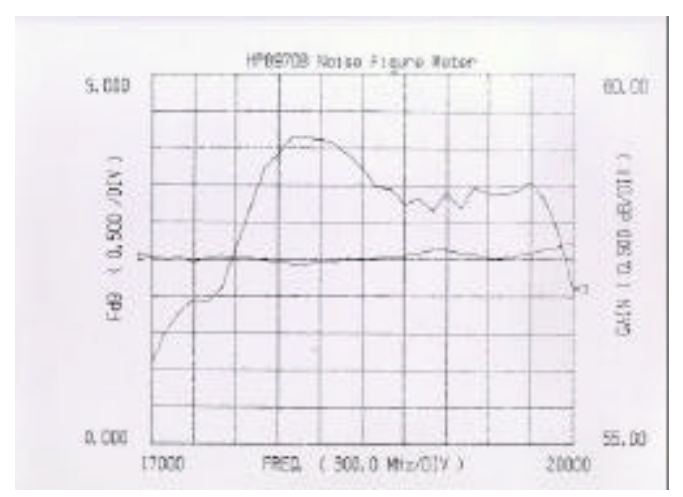

Fig. 5: Noise Figure of complete Receiver (mixer introduces approx. $0.2 \mathrm{~dB}$ degradation at ambient)

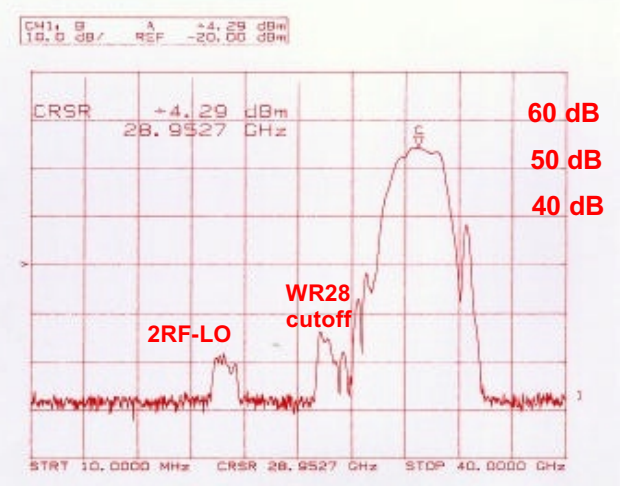

Fig. 6: Receiver wideband conversion gain response

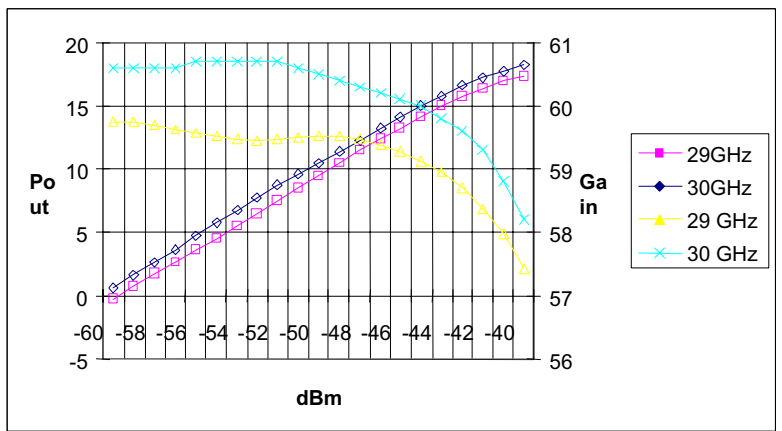

Fig. 7: Receiver gain compression; input $\mathrm{P1dB}$ is approx. $-42 \mathrm{dBm}$

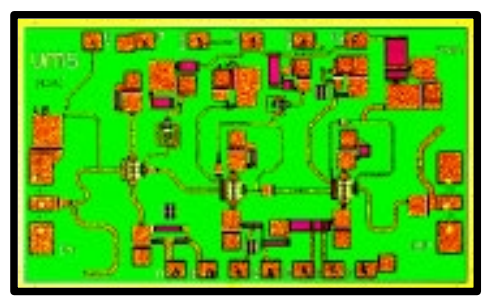

Figure 8: 18 to $32 \mathrm{GHz}$ MMIC LNA

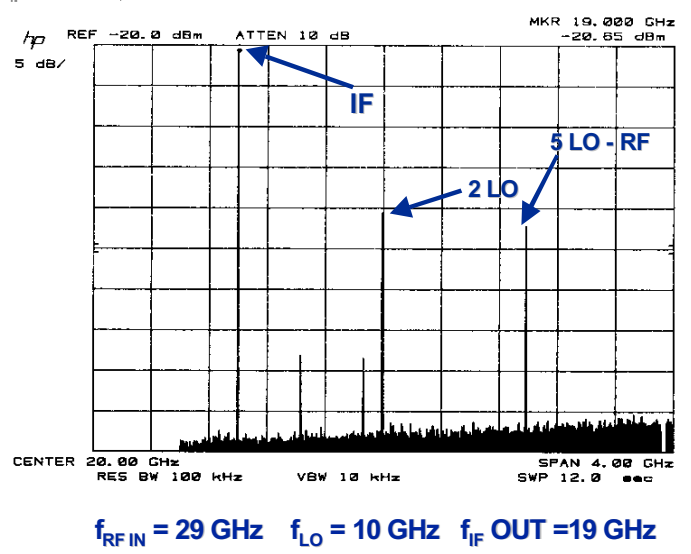

Fig. 9: Mmic mixer performance; $2 \mathrm{LO}$ level of $40 \mathrm{dBm}$ corresponds to approx. $-5 \mathrm{dBm}$ at IF output

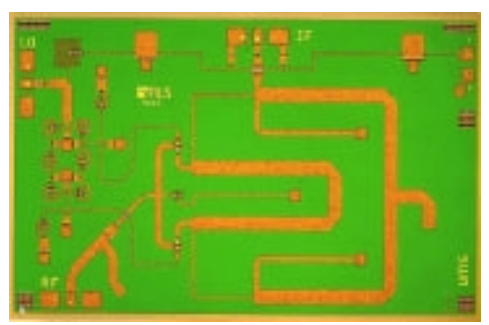

Fig. 10: 30/20 MMIC Mixer

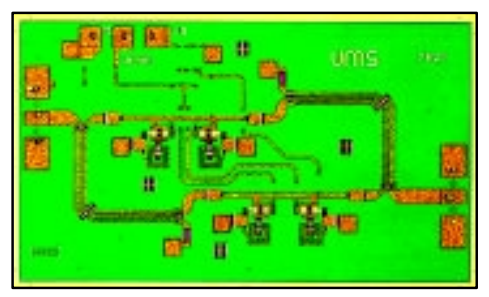

Fig. 11: 20 GHz MMIC Variable Attenuator

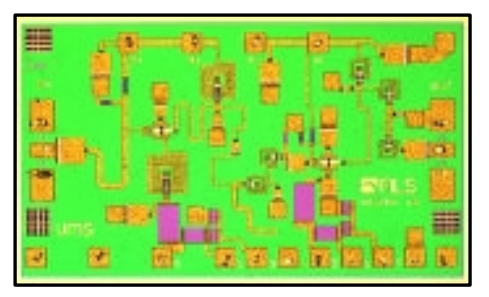

Fig. 12: MMIC Oscillator + Buffer 